\title{
ASSESSMENT OF HYBRIDIZATION AND PUSH OUT BOND STRENGTH OF FIBER POST AFTER ENDODONTIC RETREATMENT. AN INVITRO STUDY
}

\author{
Noha Adel Elkhodary* and Karim Aboubakr*
}

\begin{abstract}
Statement of the problem: Bonding procedure of fiber post to root dentin after endodontic retreatment is a challenge using total etch cement.

Objective: The aim of this invitro study was to assess hybridization and push out bond strength of fiber post after endodontic retreatment.

Materials and methods: 10 freshly extracted human canines were collected having single root canal and with the same morphology and dimensions, samples were decoronated using diamond disc under wet condition $2 \mathrm{~mm}$ above the CEJ. Endodontic treatment was then made to all samples. Samples were then inserted into resin blocks using cylinder block former and left till complete cure. Then they were randomly divided in to two groups: group I (control group) (5n) drilling was done to prepare post space followed by post cementation using total etch cement; while in group II (retreatment group) (5n) endodontic retreatment was made followed by drilling for post space preparation then post cementation was done like group one using the same cement. After post cementation samples were transversely sectioned into six sections of $1.5 \mathrm{~mm}$ thickness representing apical, middle and coronal root part. Push out test was performed using universal testing machine at $0.5 \mathrm{~mm} / \mathrm{min}$. Scanning of the root interface using SEM after bond strength test were made to detect the post cement/root interface.
\end{abstract}

Results: Regardless of the root level; Group I showed statistically significant higher mean push out bond strength (11.55 MPA) than Group II (7.93 MPA). Regardless of groups; there were no statistically significant difference between coronal (13.13 MPA) and middle root levels (9.62 MPA); both showed statistically significantly higher mean push out bond strength than apical root level (6.48 MPA). Comparing between groups at different root sections results showed; as regards coronal root level; Group I showed statistically significant higher mean push out bond strength (16.06 MPA) than Group II (10.19 MPA). While at middle as well as apical root levels; there were no statistically significant difference between mean push out bond strength values of the two groups. Scanning electron microscope revealed formation of resin tags and hybridization within the dentin in group one (GI) which was clearly found in the coronal section while in group two (GII) there was an ill-defined hybrid layer at interface. Interfacial gaps, void and remnants of resin sealer were found mainly in the apical section.

\footnotetext{
* Lecturer of Fixed Prosthodontics Department Faculty of Dentistry, Cairo University, Egypt.
} 
Conclusions: Endodontic retreatment showed significant adverse effect on fiber post push out bond strength compared to endodontically treated teeth. In endodontically treated teeth root level affected fiber post push out bond strength mainly at the apical level while in endodontically retreated teeth there was no difference in push out bond strength mean value between the different root levels. Interface of the endodontically treated teeth showed hybrid layer formation and resin tags coronally while in endo retreatment gaps and void were seen at the interface.

KEY WORDS: Endodontic retreatment, Fiber post, Push out test.

\section{INTRODUCTION}

Restoration of endodontically treated teeth have been found to be one of the major concerns that affect the prognosis of the tooth. Post and core systems have been widely used nowadays in endodontically treated teeth with coronal tooth structure loss in order to improve the retention of the restoration ${ }^{(1,2)}$. Fiber posts have been widely used because of their advantages over the metal posts including the similar modulus of elasticity to dentine which decreases the stress on the root surface and allowing adequate distribution of the masticatory forces thus decreasing the possibility of root fracture as well as being a tooth colored post that can be bonded to tooth structure in addition to being a retrievable post helped in solving the unaesthetic problem of metal posts ${ }^{(3)}$. Uthappa et al in $2015^{(4)}$ made a clinical comparative evaluation between metal and fiber posts in restoring endodontically treated teeth and found that metal post showed higher failure rates when compared to fiber post.

Adhesive resin cement have been used to cement glass fiber post because of its simplified technique and also as it decreases the nano-leakage through the demineralization of the smear layer. There are different types of adhesive resin cements that are used for fiber post cementation which include: total etch, self-etch and self-adhesive resin cements; studies have shown contradictory results about the adhesive capability of each system where some studies showed that self-adhesive system showed lowest adhesive capability when compared to total etch while others have shown that both had similar adhesive capability ${ }^{(7,8)}$. However a recent study done by Theodor, Koesmaningati and Gita in $2017^{(9)}$ compared the adhesive capability of the three adhesive systems and stated that the total etch system showed significantly better adhesive capability than self-adhesive system and this was due to the acid etch that is applied in the total etch system which resulted in the demineralization of dentine and allowed the formation of a deeper hybrid layer and resin tag formation than self-adhesive; whereas the total etch showed a higher non-significant adhesive capability than self-etch and this was correlated to technique sensitivity of the total etch procedure.

Success rate of endodontic treatment have been reported to be from $80-85 \%{ }^{(10)}$. Failure of endodontic treatment may be due to improper endodontic treatment, salivary or bacterial microleakage, improper cleaning or obturation or persistent root infection which will require further endodontic retreatment in order to be able to maintain the teeth in the dental arch. Endodontic retreatment should be done carefully with complete removal of the preexisting filling material to allow for proper instrumentation and effective disinfection but without excessive loss or damage to the dentine as studies have shown a direct relation between the strength of the root and the remaining amount of dentine ${ }^{(11,12)}$. Missau et al in $2017^{(13)}$ studied the effect of endodontic treatment and retreatment on the fatigue failure load of human canine teeth and found that both endodontic treated canines and those with retreatment behaved the same in terms of fatigue failure loads and number of cycles to failure.

In endodontic retreatment the action of using drills to remove the gutta percha results in forming 
a new smear layer in the canal rich with remnants of gutta percha and sealer which will be plasticized by heat obtained due to friction which in combination with inorganic components can occlude the dentinal tubules affecting the bonding of the fiber post ${ }^{(14,15)}$. Adequate and complete removal of this smear layer and these materials has not yet been established by any of the retreatment procedures ${ }^{(16,17)}$.

A systematic review was done in $2019^{(18)}$ to asses weather endodontic retreatment would affect the fracture strength of endodontically treated teeth and they stated that endodontic retreatment may affect the mechanical properties of endodontically treated teeth, however they declared that more studies are needed in this field to completely comprehend such matter.

So the aim of this study was to assess hybridization and push out bond strength of fiber post after endodontic retreatment.

The first null hypothesis was that endodontic retreatment would not affect the push out bond strength of fiber post and the second null hypothesis was that there would be no difference in the push out bond strength of fiber post at different root levels in both endodontically treated and retreated teeth.

\section{MATERIALS AND METHODS}

\section{Specimen preparation}

10 freshly extracted human maxillary canines were collected from oral surgery department in Faculty of dentistry; Cairo University. Teeth were selected according to inclusion criteria, having similar root morphology and dimension, with single root canal, free from internal resorption, caries, fracture, calcification or cracks. The dimensions were measured buccolingually and mesiodistally using digital caliper with accepted variation of 1-1.5mm ${ }^{(19)}$ (Fig.1). The teeth collected had no previous endodontic treatment based on clinical and radiographic examination. The teeth were stored in saline solution at room temperature. Decoronation of teeth were made using diamond disc under wet condition $2 \mathrm{~mm}$ above the CEJ. Endodontic treatment was made to all samples by the same operator and under the supervision of an endodontic expert. Working length was determined visually $1 \mathrm{~mm}$ shorter than the length of the canal. Cleaning and shaping was done by protaper universal rotary system (Dentsply, Maillefer, Ballaigues, Switzerland) using the crown down technique in the following sequence: shaping files

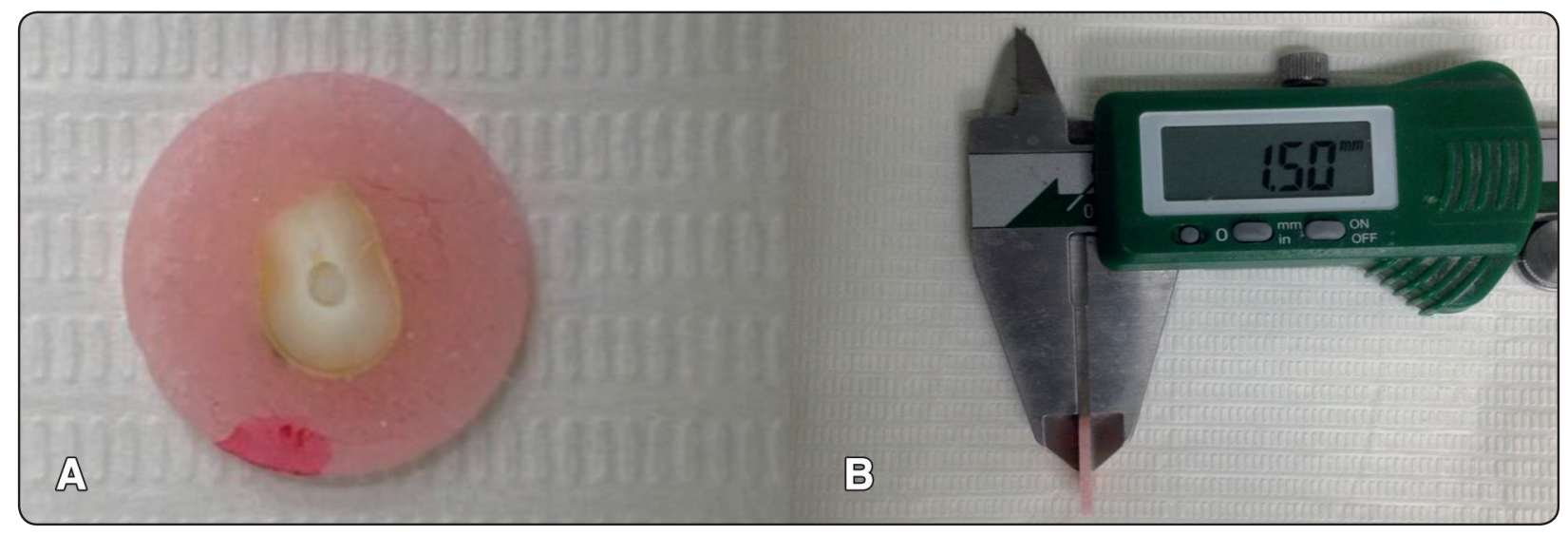

Fig. (1) A: Transverse section of the sample to be to be tested, B: Caliber to check the thickness of the sample slice. 
$\mathrm{S} 1$ and $\mathrm{S} 2$ in a brushing motion then the finishing files F1, F2, F3 up to finishing F4 file (size 40 with $6 \%$ apical taper) in picking motion using Xsmart plus endomotor (Dentsply, Maillefer, Ballaigues, Switzerland). Torque and speed were set according to the manufacturer instructions $(2 \mathrm{~N} / \mathrm{cm}$ torque and a constant speed of $300 \mathrm{rpm}$ ). Irrigation was done during treatment first by $5 \mathrm{ml} 2.5 \%$ sodium hypochlorite for one minute followed by $5 \mathrm{ml} 17$ $\%$ EDTA for one minute then a final flush with saline for $1 \mathrm{~min}$. Root canal was dried using paper points before obturation with gutta percha cones F4 (Dentsply, Maillefer, Ballaigues, Switzerland) using resin sealer (ADSEAL Meta, biomed, Korea) the access cavity was then sealed using temporary resin cement (Tempolink clear, Detax, Ettlingen, Germany). Teeth were stored for one week in saline solution at room temperature to allow complete setting of the sealer. All Samples were inserted into resin blocks using cylinder block former and left till complete cure.

Samples were then numbered from 1 to 10 and divided by www.random.org into two equal groups at allocation ratio 1:1 and sealed in a closed envelope to avoid selection bias and to allow samples to have equal chances to be in the control group or the retreatment group.

In group one (GI; control group) post space preparation was made one week after the endodontic treatment using peso drills size 2, 3, and 4 for partial removal of gutta percha leaving $5 \mathrm{~mm}$ apical for apical seal and confirmed by radiograph. A post space was prepared with the calibration drill included in post kit corresponding to the post size, each canal was irrigated using $5 \mathrm{ml} 2.5 \%$ sodium hypochlorite for one minute followed by $5 \mathrm{ml} 17$ $\%$ EDTA followed by a final flush with sodium hypochlorite and then dried using paper points.

Fiber post (GLASSIX plus, Nordin, Switzerland) cementation was done using total etch dual cure adhesive resin cement (Cement-it adhesive cement: Pentron, Batch no: 4717117, USA); first cleaning of fiber post was made using $70 \%$ alcohol this was followed by $37 \%$ phosphoric acid etching for 15 sec and then silanized with DentoBond Porcelain Fix (Itena, France) for 60 seconds then dried with a light jet of air, phosphoric acid etching 37\% concentration was applied to the canal walls at post space using plastic needle for $15 \mathrm{sec}$. then irrigation with air water spray followed by dryness with paper point. Application of bonding agent single bond universal adhesive (3M GmbH, Neuss, Germany) for $20 \mathrm{sec}$ using microbrush, removal of excess by paper point then air dried with gentle air pressure and light cured for $10 \mathrm{sec}$. Application of cement using lentulo spiral and also applied to the post using the supplied tips. The post was positioned in place by firm finger pressure, excess cement was removed by microbrush followed by light curing (LED) with light emitting of $1200 \mathrm{mw} / \mathrm{cm}^{2}$ for $20 \mathrm{sec}$. in all directions using Woodpecker i-led (Woodpecker, China). Sealing of the access was done with flowable composite (Polofil NHT flow, Voco, Germany). Samples were preserved in saline solution at room temperature for one week till push out test.

In group two (GII; retreatment group) endodontic retreatment was made using D1, D2 and D3 files (Protaper Universal Retreatment; Dentsply Maillefer, Ballaigues, Switzerland) sequentially with the crown-down technique at torque and speed settings recommended by the manufacturer $(2 \mathrm{~N} / \mathrm{cm}$ torque and a constant speed of $300 \mathrm{rpm}$ ) until the required depth was achieved in all specimens, finishing was done by $\mathrm{f} 4$ protaper universal file; irrigation and filling of the root canal was made followed by post space preparation and fiber post cementation as in group I (GI). And then preserved in saline solution at room temperature for one week till push out test.

Before push out test, samples from each group were sectioned transversely into slices of $1.5 \mathrm{~mm}$ thickness each representing coronal, middle and apical third for each group leaving the last $6 \mathrm{~mm}$ 
from the apex using cutting machine under wet condition (Isomet; Buehler Ltda.). Each slice was marked for the detection of the coronal side during the pushout test.

Push out test was made using computer controlled materials testing machine (Model 3345; Instron Industrial Products, Norwood, MA, USA). Each section was mounted on the instron and subjected to compressive loading in an apicocoronal direction at a crosshead speed of $0.5 \mathrm{~mm} / \mathrm{min}$ and a load cell of $5 \mathrm{kN}$ and the force required to debond the post was recorded in newton $(\mathrm{N})$. The load cell is centered at the post away from dentine surface.

Push out bond strength was calculated using the following equation:

Push out bond strength $=F / A$ where: $A=\pi H(r 1+r 2)$

Where $\pi$ is the constant $3.14, \mathrm{H}=1.5 \mathrm{~mm}$ which is the thickness of the slice, $\mathrm{r} 1$ is the coronal radius of the slice and $\mathrm{r} 2$ is the apical radius.

Both the statistician and the assessors were blinded in order to minimize the risk of bias.

\section{Scanning electron microscope}

Surface image interface was scanned using Quanta FEG 250 scanning electron microscope (FEI company, USA)*. Samples were mounted onto SEM stubs. SEM conditions were: $10.1 \mathrm{~mm}$ working distance, with in-lens detector with an excitation voltage of $10 \mathrm{KV}$ and 1000x magnification for studying the hybrid layer formation and root interface.

\section{RESULTS}

Numerical data were explored for normality by checking the distribution of data and using tests of normality (Kolmogorov-Smirnov and Shapiro-Wilk tests). Data showed normal (parametric) distribution. Data were presented as mean and standard deviation (SD) values and 95\% Confidence Interval (95\% CI). Repeated measures Analysis of Variance (ANOVA) was used to study the effect of group, root level and their interaction on mean push out bond strength. Bonferroni's post-hoc test was used for pair-wise comparisons when ANOVA test is significant. The significance level was set at $\mathrm{P} \leq 0.05$. Statistical analysis was performed with IBM SPSS Statistics for Windows, Version 23.0. Armonk, NY: IBM Corp.

\section{Repeated measures ANOVA results}

The results showed that group regardless of root level had a statistically significant effect on mean push out bond strength. Root level regardless of group had a statistically significant effect on mean push out bond strength. The interaction between the variables had no statistically significant effect on mean push out bond strength. Since the interaction between the variables is non-statistically significant, so the variables are independent from each other. (Table 1)

TABLE (1) Repeated measures ANOVA results for the effect of different variables on mean push out bond strength

\begin{tabular}{llllllc}
\hline Source of variation & $\begin{array}{l}\text { Type III Sum } \\
\text { of Squares }\end{array}$ & Df & Mean Square & $F$-value & $P$-value & $\begin{array}{c}\text { Effect size } \\
\text { (Partial eta squared) }\end{array}$ \\
\hline Group & 98.468 & 1 & 98.468 & 11.843 & $0.009^{*}$ & 0.597 \\
Root level & 221.256 & 2 & 110.628 & 12.909 & $<0.001^{*}$ & 0.617 \\
Group x Root level interaction & 28.452 & 2 & 14.226 & 1.660 & 0.221 & 0.172 \\
\hline
\end{tabular}

df: degrees of freedom $=(n-1), *:$ Significant at $P \leq 0.05$ 


\section{Effect of group regardless of root level}

Regardless of root level; Group I showed statistically significantly higher mean push out bond strength than Group II ( $P$-value $=0.009$, Effect size $=0.597)$. $($ Table 2$)$

TABLE (2) The mean, standard deviation (SD) values and results of repeated measures ANOVA test for comparison between push out bond strength (MPa) of the two groups regardless of root level

\begin{tabular}{|c|c|c|c|c|c|}
\hline \multicolumn{2}{|c|}{ Group I } & \multicolumn{2}{c|}{ Group II } & \multirow{2}{*}{$P$-value } & $\begin{array}{c}\text { Effect size } \\
(\text { Partial eta } \\
\text { squared })\end{array}$ \\
\hline Mean & SD & Mean & SD & & 0.597 \\
\hline 11.55 & 5 & 7.93 & 2.71 & $0.009^{*}$ & 0.50 \\
\hline
\end{tabular}

*: Significant at $P \leq 0.05$

\section{Effect of root level regardless of group}

Regardless of group; there was a statistically significant difference between mean push out bond strength at different root levels $(P$-value $<0.001$, Effect size $=0.617$ ). Pair-wise comparisons revealed that there was no statistically significant difference between coronal and middle root levels; both showed statistically significantly higher mean push out bond strength than apical root level. (Table 3)

\section{Interactions of variables:}

\section{Comparison between groups}

As regards coronal root level; Group I showed statistically significantly higher mean push out bond strength than Group II $(P$-value $=0.018$, Effect size $=0.526$ ). While at middle as well as apical root levels; there was no statistically significant difference between mean push out bond strength values of the two groups ( $P$-value $=0.094$, Effect size $=0.310)$ and $(P$-value $=0.464$, Effect size $=$ 0.069 ), respectively. (Table 4 )

TABLE (3) The mean, standard deviation (SD) values and results of repeated measures ANOVA test for comparison between push out bond strength values (MPa) at different root levels regardless of group

\begin{tabular}{|c|c|c|c|c|c|c|c|}
\hline \multicolumn{2}{|c|}{ Coronal } & \multicolumn{2}{c|}{ Middle } & \multicolumn{2}{c|}{ Apical } & \multirow{2}{*}{ P-value } & $\begin{array}{c}\text { Effect size (Partial eta } \\
\text { squared) }\end{array}$ \\
\hline Mean & SD & Mean & SD & Mean & SD & & 0.617 \\
\hline
\end{tabular}

*: Significant at $P \leq 0.05$, Different superscripts are statistically significantly different

TABLE (4) The mean, standard deviation (SD) values and results of repeated measures ANOVA test for comparison between push out bond strength values (MPa) of the two groups at each root level

\begin{tabular}{|c|c|c|c|c|c|c|}
\hline \multirow{2}{*}{ Root level } & \multicolumn{2}{|c|}{ Group I } & \multicolumn{2}{|c|}{ Group II } & \multirow{2}{*}{$P$-value } & \multirow{2}{*}{$\begin{array}{c}\text { Effect size } \\
\text { (Partial Eta Squared) }\end{array}$} \\
\hline & Mean & SD & Mean & SD & & \\
\hline Coronal & 16.06 & 4 & 10.19 & 1.78 & $0.018^{*}$ & 0.526 \\
\hline Middle & 11.56 & 3.88 & 7.68 & 2.42 & 0.094 & 0.310 \\
\hline Apical & 7.04 & 2.34 & 5.92 & 2.27 & 0.464 & 0.069 \\
\hline
\end{tabular}

*: Significant at $P \leq \mathbf{0 . 0 5}$, 


\section{Comparison between root levels}

As regards Group I; there was a statistically significant difference between mean push out bond strength values at different root levels $(P$-value $=$ 0.001 , Effect size $=0.846$ ). Pair-wise comparisons revealed that there was no statistically significant difference between coronal and middle root levels; both showed statistically significantly higher mean push out bond strength than apical root level.

While in Group II; there was no statistically significant difference between mean push out bond strength values at different root levels $(P$-value $=$ 0.082 , Effect size $=0.511)$. (Table 5)

\section{Scanning electron microscope:}

Scanning electron microscope revealed formation of resin tags and hybridization within the dentine in group one (G1) which was clearly found in the coronal section however in the apical section resin tag formation was found but with decreased density and ill-defined hybrid layer (Fig.2). In group two (G2) there was an ill-defined hybrid layer and resin cement was not well adapted to dentine at interface where interfacial gaps, voids and remnants of resin sealer in addition to multiple smear plugs were found which was clearly identified mainly in the apical section. (Fig.3)

TABLE (5) The mean, standard deviation (SD) values and results of repeated measures ANOVA test for comparison between push out bond strength values (MPa) at different root levels within each group

\begin{tabular}{|l|c|c|c|c|}
\hline \multirow{2}{*}{ Root level } & \multicolumn{2}{|c|}{ Group I } & \multicolumn{2}{c|}{ Group II } \\
\cline { 2 - 5 } & Mean & SD & Mean & SD \\
\hline Coronal & $16.06^{\mathrm{A}}$ & 4 & 10.19 & 1.78 \\
\hline Middle & $11.56^{\mathrm{A}}$ & 3.88 & 7.68 & 2.42 \\
\hline Apical & $7.04^{\mathrm{B}}$ & 2.34 & 5.92 & 2.27 \\
\hline P-value & \multicolumn{2}{|c|}{$0.001^{*}$} & \multicolumn{2}{c|}{0.082} \\
\hline $\begin{array}{l}\text { Effect size } \\
\text { (Partial Eta Squared })\end{array}$ & \multicolumn{2}{|c|}{0.846} & \multicolumn{2}{|c|}{0.511} \\
\hline
\end{tabular}

*: Significant at $P \leq 0.05$, Different superscripts in the same column indicate statistically significant difference between root levels

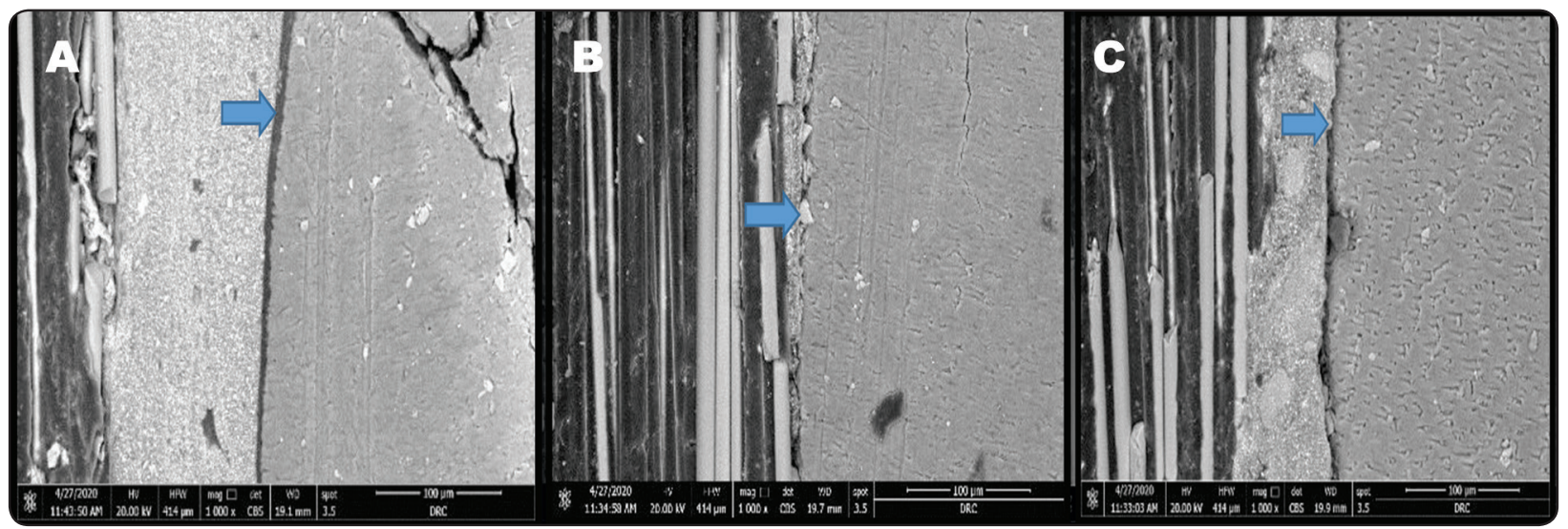

Fig. (2) SEM for the control group (G1), A: Coronal section Arrow: hybrid layer and resin tag. B: Middle section; Arrow: resin. C: Apical section; Arrow: ill-defined hybrid layer 


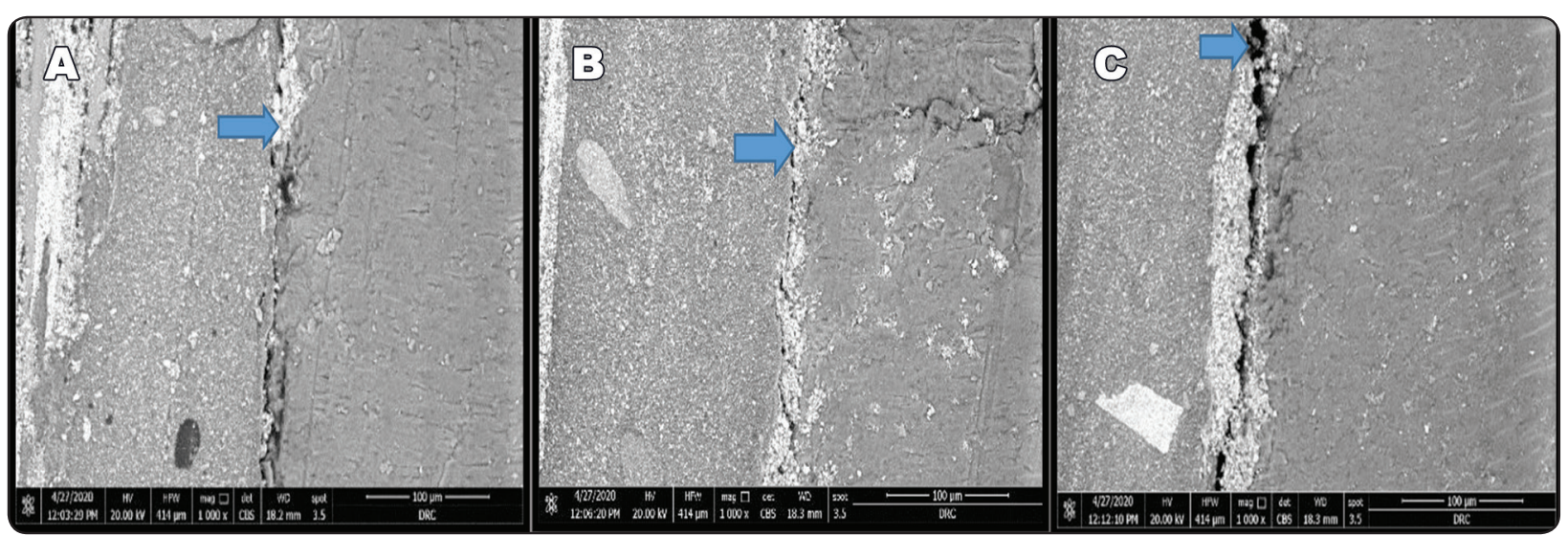

Fig. (3): SEM for retreatment group A: Coronal section; Arrow: remnants of resin sealer, B: Middle section Arrow: ill-defined hybrid layer .C: apical section; Arrow: Void

\section{DISCUSSION}

The purpose of this study was to assess hybridization and push out bond strength of fiber post after endodontic retreatment.

Endodontic treatment requires complete and efficient removal of necrotic pulp tissues, cleansing efficacy depends on multiple things one of which is the instrumentation procedure; in this study protaper system was used for removal of pulpal tissues; a study done by Elnagar MH, Ghoname NA and Ghoneim $\mathrm{WM}$ in $2018^{(20)}$ stated that a better cleanliness was achieved when rotary system was used when compared to manual instrumentation technique. Also a systematic review done by Peralta-Mamani et al in $2019^{(21)}$ stated that rotary instrumentation showed better centralization, less alterations in working length and canal curvatures, better cleaning ability and debris removal in addition to better attaining of regular canal shape than manual instrumentation. Endodontic retreatment is required in cases where previous endodontic treatment failed, in order to maintain the tooth in the dental arch. Endodontic retreatment has been reported to be a treatment of predictable prognosis with a success rate of $80 \%$ to $88 \%$ when well performed, thus becoming a prior treatment option to tooth extraction ${ }^{(22)}$.

In this study protaper universal retreatment kit (D1, D2 and D3 files (Protaper Universal
Retreatment; Dentsply Maillefer, Ballaigues, Switzerland)) was used for endodontic retreatment as studies have shown its effectiveness in removal of the filling material as well as being faster and easier in penetration which facilitates the removal of gutta percha and sealer ${ }^{(23-26)}$. Solvents was not used in removal of the gutta percha as studies showed that using solvents will result in a layer of gutta percha and sealer at root canal walls that may not be easily removed or even detected ${ }^{(27,28)}$.

Restoration of endodontically treated teeth may require post placement to provide retention for the core. There are many types of posts available nowadays; however glass fiber post have gained popularity due to its modulus of elasticity being close to that of dentine and the ease of being adhesively bonded to dentine using adhesive resin cement thus allowing a more homogenous stress distribution and decreasing the possibility of catastrophic root fracture $^{(29,30)}$. Bonding mechanism depend on hybrid layer formation and resin tag which offers bonding to dentin. Cleaning of fiber post was made using $70 \%$ alcohol to remove any contaminants during try in procedure this was followed by $37 \%$ phosphoric acid etching for $15 \mathrm{sec}$ and then silanized with ceramic primer (3M ESPE, St. Paul) for 60 seconds to increase the bond between the cement and the post. 
Irrigation regimen is known to affect the canal surface characteristics and failure of removal of the smear layer will result in formation of a deficient hybrid layer and consequently poor adhesion and apparent interfacial gap ${ }^{(31)}$. In this study Irrigation was done first with $5 \mathrm{ml} 2.5 \%$ sodium hypochlorite for one minute to dissolve organic material and smear layer in addition to its antimicrobial action $^{(32)}$, followed by $5 \mathrm{ml} 17 \%$ EDTA which is responsible for removal of the inorganic component of the smear layer due to its chelating powder ${ }^{(33)}$. This was followed with a final flush using sodium hypochlorite to remove residual of EDTA and stop its chelating action.

One of the most important factors affecting the bond strength of the fiber post to root dentine is the adhesive cement used; in this study total etch system have been used as studies have shown that it had better adhesive capability than other adhesive systems. This may be due to the acid etch applied which resulted in the demineralization of dentine and allowed for the formation of a deeper hybrid layer and resin tag formation, etching also removes the smear layer, demineralize hydroxyapatite matrix exposing the collagen and dentinal tubule so allow good bonding when the monomer in the bonding agent penetrate the dentin and collagen fibers forming hybrid layer and resin tags ${ }^{(9)}$.

Push out test was done in this study to determine the adhesive capability for the adhesively cemented fiber post as researchers have found it to be a more effective and reliable method than microtensile test as the later showed a higher risk of specimens destruction ${ }^{(34-37)}$.

Results of the current study showed that endodontic retreatment adversely affect fiber post bond strength, thus the null hypothesis that endodontic retreatment would not affect fiber post push out bond strength was rejected.

Results of this study showed that Group I (endodontic treatment) showed statistically significantly higher mean push out bond strength (11.55 MPA) than Group II (endodontic retreatment) (7.93 MPA) and this may be due to the inability to ensure the complete removal of the filling material from the root canal as several studies have stated that regardless the technique used for retreatment and the use of solvent, it is difficult to completely remove the resin sealer tags from the root canal as it is deeply penetrated into the dentinal tubules ${ }^{(38,39)}$.

The results of this study were in agreement with other studies as Pelegrine et al in $2016^{(40)}$ who performed a study to determine the bond strength of fiber post in endodontically retreated teeth, and found that endodontic retreatment had an adverse effect on the push out bond strength of fiber post when compared to endodontically treated teeth; a study done by Pereira et al in $2019^{(41)}$ who found that endodontic retreatment negatively affected the cement penetration and also the fiber post bond strength. Also a systematic review that was done by Schestatsky et al in $2019^{(18)}$ which concluded that endodontic retreatment showed a lower mechanical performance than endodontically treated teeth.

Regarding the post push out bond strength at different root levels; there was a statistically significant difference between mean push out bond strength at different root levels. In group I there was no statistically significant difference between coronal and middle root levels; both showed statistically significantly higher mean push out bond strength than apical root level while in group II there was no statistically significant difference between mean shear bond strength values at different root levels. Thus the second null hypothesis was partially rejected.

The difference in the fiber post bond strength at different root levels with higher bond strength at the coronal part have been attributed due to many reasons as the coronal dentine showed a more dense and wider diameter tubules than the middle and apical root level allowing for a stronger adhesion and more penetration of the resin into the tubules ${ }^{(42,43)}$. 
In addition to other methodological factors which may also affect the bond strength as the accessibility of the coronal portion making the application of the etch and adhesive more easier in addition to proper light transmission which ensure complete resin polymerization, while at the middle and apical regions there is a decrease in the light energy transmission which will affect the resin polymerization in these regions, in addition to the effect of moisture contamination and over drying after etching ${ }^{(39,41,42)}$. The results were in agreement with other studies which attributed a higher bond strength of fiber post at the coronal dentin ${ }^{(46-53)}$.

Scanning electron microscope was done in this study to determine the bonding surface quality and it revealed resin tag formation and hybrid layer which was clearly identified in the coronal sample of group one, while differences of resin tag density were found in middle and apical parts of group one while in group two there was few resin tags at the coronal area with evidence of remnants of resin sealer on the root dentine at middle and apical areas, and this may be attributed to the decrease in diameter and quantity of the dentine as we move apically resulting in difficult accessibility and ineffective cleaning in addition to smear layer on dentine surface which is not cleaned completely resulting in a more superficial hybrid layer and resin tags ${ }^{(54-57)}$. This was observed by other authors who found that specimens from endodontically retreated teeth showed remnants of filling material of primary treatment mainly in the apical region ${ }^{(23,38,58)}$.

The limitations of this study include being an invitro study in addition to not applying fatigue loading and thermocycling to simulate clinical conditions.

\section{CONCLUSIONS}

Within the limitations of this study the following conclusions could be drawn:

1. Endodontic retreatment showed an adverse effect on fiber post push out bond strength compared to endodontic treatment.
2. In endodontically treated teeth root level affected fiber post push out bond strength mainly at the apical level.

3. Different root levels in endodontically retreated teeth showed no difference in push out bond strength mean value.

4. Interface of the endodontically treated teeth showed hybrid layer formation and resin tags while in endo retreatment, gaps and voids were clearly seen at the interface.

\section{REFERENCES}

1. Perdigao J, Gomes G, Augusto V. The effect of dowel space on the bond strengths of fiber posts. J Prosthodont 2007;16(3):154-164.

2. Nova V, Karygianni L, Altenburger MJ, Wolkewitz M, Kielbassa Am, Wrbas KT. Pull out bond strength of fiber reinforced composite post system luted with self-adhesive resin cement. J dent 2013;41(11):1020-1026.

3. Qualtrough AJ, Mannocci F: Tooth-colored post system: a review. Oper Dent 2003;28:86-91.

4. Santos AF, Meira JB, Tanaka CB, et al: Can fiber posts increase root stresses and reduce fracture? J Dent Res 2010;89:587-591.

5. Uthappa R, Mod D, Kharod P, Pavitra S, Ganiger K, Kharod $\mathrm{H}$. Comparative evaluation of the metal post and fiber post in the restoration of the endodontically treated teeth. $\mathrm{J}$ Dent Res Rev 2015;2:73-7.

6. Soares CJ, Raposo LH, Soares PV, Santos-Filho PC, Menezes MS, SoaresPB, Magalhaes D. Effect of different cements on the biomechanical behavior of teeth restored with cast dowel-and-cores-in vitro and fea analysis. J Prosthodont 2010;19:130-137.

7. Hochman N, Feinzaig I and Zalkind M 2003 Effect of design of pre-fabricated posts and post heads on the retention of various cements and core materials.J. Oral Rehab. 30 $702-7$.

8. Monticelli F, Ferrari M and Toledano M 2008 Cement system and surface treatment selection for fiber post luting. Med. Oral Patol. Oral Cir. Bucal. 13 E214-21.

9. Theodor Y, Koesmaningati H, Gita F. Adhesive capability of total-etch, self-etch, and self-adhesive systems for fiber post cementation. IOP Conf. Series: Journal of Physics: Conf. Series 884 (2017);1-7. 
10. Sjögren U, Figdor D, Persson S, et al. Influence of infection at the time of root filling on the outcome of endodontic treatment of teeth with apical periodontitis. Int Endod J 1997;30:297-306.

11. Sagsen B, Er O, Kahraman Y, et al. Resistance to fracture of roots filled with three different techniques. Int Endod J 2007;40:31-5.

12. Dimitriu B, Varlan C, Suciu I, et al. Current considerations concerning endodontically treated teeth: alteration of hard dental tissues and biomechanical properties following endodontic therapy. J Med Life 2009;2:60-5.

13. Missau T, De Carlo Bello M, Michelon C, Mastella Lang P, Pereira GK, Baldissara P, Valandro LF, Souza Bier CA, Rippe MP. Influence of Endodontic Treatment and Retreatment on the Fatigue Failure Load, Numbers of Cycles for Failure, and Survival Rates of Human Canine Teeth. J Endod 2017;43:2081-2087.

14. Serafino C, Gallina G, Cumbo E, Ferrari M. Surface debris of canal walls after post space preparation in endodontically treated teeth: A scanning electron microscopic study. Oral Surg oral Med Oral Pathol Oral Radiol Endod 2004;97(3): 381-387.

15. Piriani G, Pratic C. Effectiveness of three different retreatment techniques in canals filled with compacted gutta percha or thermafil: a scanning electron microscope study. J Endod 2009:35(10):1433-1440.

16. Giuliani V, Cocchetti R, Pagavino G. Efficacy of protaper universal retreatment files in removing filling materials during root canal retreatment. J Endod 2008;34(11):1381-1384.

17. Fruchi LC, Zapata RO, Cavenago BC, Duarte MAH, Bueno CES, Martin AS. Efficacy of reciprocating instruments for removing filling material in curved canals obturated with a single-cone technique: a micro-computed tomographic analysis. J Endod 2014;40(7):1000-1004.

18. Schestatsky R, Dartora G, Felberg R, Spazzin AO, -Onofre RS, Bacchi A, Pereira GKR. Do endodontic retreatment techniques influence the fracture strength of endodontically treated teeth? A systematic review and meta-analysis. Journal of the Mechanical Behavior of Biomedical Materials 2019;90:306-312.

19. Soares CJ, Martins LRM, Fonseca RB, Correr-Sobrinho L, Fernandes-Neto AJ. Influence of cavity preparation design on fracture resistance of posterior Leucite-reinforced ceramic restorations. J Prosthet Dent 2006;95(6):421-429.
20. Elnagar MH, Ghoname NA, Ghoneim WM. Cleaning efficacy of rotary versus manual system for root canal preparation in primary teeth. Tanta Dental Journal 2018;15:14-18

21. Mamani MP, Rios D, Durate MAH, Junior JFS, Honorio HM. Manual vs rotary instrumentation in endodontic treatment of permanent teeth. Am J Dent 2019;32:311-324.

22. Imura N, Pinheiro ET, Gomes BP, Zaia AA, Ferraz CCR, Souza Filho FJ. The outcome of endodontic treatment: a retrospective study of 2000 cases performed by a specialist. J Endod. 2007;33:1278-1282.

23. Duarte MA, So MV, Cimadon VB, Zucatto Z, Vier-Pelisser FV, Kuga MC. Effectiveness of rotatory or manual techniques for removing a 6-year-old filling material. Braz Dent J. 2010;21:148-152.

24. So MVR, Saran C, Magro ML, Pelisser FVV, Munhoz M. 2008. Efficacy of ProTaper Retreatment system in root canals filled with gutta-percha and two endodontic sealers. J Endod 2010;34:1223-1225.

25. Takahashi CM, Cunha RS, de Martin AS. In vitro evaluation of the effectiveness of ProTaper universal rotary retreatment system for gutta-percha removal with or without a solvent. J Endod 2009;35: 1580-1583.

26. Rodig T, Hausdorfer T, Konietschke F, Dullin C, Hahn W, Hulsmann M. Efficacy of D-RaCe and ProTaper universal retreatment $\mathrm{NiTi}$ instruments and hand files in removing gutta-percha from curved root canals - A micro-computed tomography study. Int Endod J. 2012; 45:580-589.

27. Wilcox LR, Juhlin JJ, Endodontic retreatment of thermafil versus laterally condensed gutta percha. J Endod 1994;20(3):115-117.

28. Horvath SD, Altenburger MJ, Naumann M, Wolewitz M, Schirrmeister JF. Cleanliness of dentinal tubules following gutta percha removal with and without solvents: a scanning electron microscopic study. Int Endod J 2009;42(11): 1032-1038.

29. Naumann M, Preuss A, Frankenberger R. Load capability of excessively flared teeth restored with fiberreinforced composite posts and all-ceramic crowns. Oper Dent 2006;31:699e704.

30. Naumann M, Preuss A, Frankenberger R. Load capability of excessively flared teeth restored with fiberreinforced composite posts and all-ceramic crowns. Oper Dent 2006;31:699-704.

31. Silva RS., Antunes RPA., Ferraz CR. and Orsi LA. The effect of the use of $2 \%$ chlorohexidine gel in post space preparation on carbon fiber post retention. Oral Surg Oral Med Oral Pathol Oral Radiol Endod. 2005;99:372-7. 
32. Mohammadi Z. Sodium hypochlorite in endodontics: an update review. Int Endod J. 2008;58(6):329-41.

33. Doumani M., Habib A., Douman A. Seirawan MK., Sadeka MA. and Alnofiai SR. A Review: The Applications of EDTA in Endodontics (Part I). IOSR Journal of Dental and Medical Sciences. 2017;16(9): 83-85.).

34. Goracci C, Tavares AU, Fabianelli A, Monticelli F, Raffaelli O, Cardoso PC, Tay F, Ferrari M. The adhesion between fiber posts and root canal walls: Comparison between microtensile and push-out bond strength measurements. Eur J Oral Sci. 2004 Aug;112(4):353-61

35. Radovic I, Mazzitelli C, Chieffi N and Ferrari M. Evaluation of the adhesion of fiber posts cemented using different adhesive approaches. Eur. J. Oral Sci. 2008;116:557-63.

36. Wang Z, Ji Y and Zhang F. Bond strengths of an epoxy resinbased fiber post with four adhesive systems. Quintessence Int. 2010;41:173-80.

37. Farina AP, Cecchin D, Garcia Lda F, Naves LZ, Sobrinho LC, Pires-de-Souza Fde C. Bond Strength of Fiber Post In Different Root Thirds Using Resin Cement.J Adhes Dent. 2011 Apr;13(2):179-86.

38. Gu LS, Ling JQ, Wei X, Huang XY. Efficacy of ProTaper Universal rotary retreatment system for gutta-percha removal from root canals. Int Endod J. 2008;41:288-295.

39. Xu LL, Zhang L, Zhou XD, Wang R, Deng YH, Huang DM. Residual filling material in dentinal tubules after gutta-percha removal observed with scanning electron microscopy. J Endod. 2012; 38: 293-296.

40. Pelegrine RA, Paulillo LMS, Kato AS, Fontana CE, Pinheiro SL, Martin AS and Bueno CE. Effect of endodontic retreatment on push-out bond strength and quality of fiber postbonding interface of resin cements. J Contemp Dent Pract 2016;17(1):42-48.

41. Pereira KF, Vencão AC, Magro MG, Belizário LG, Porto TS, Andrade MF, Duarte MAH, Kuga MC. Effect of endodontic retreatment on the bond strength of resin cements to root canal dentin. Am J Dent. 2019 Jun;32(3):147-151.

42. Topcu FT, Erdemir U, Sahinkesen G, Mumcu E, Yildiz E, Uslan I. Push-out bond strengths of two fiber post types bonded with different dentin bonding agents. J Biomed Mater Res B Appl Biomater 2010;93:359-66.

43. Vichi A, Grandini S, Davidson CL, Ferrari M. An SEM evaluation of several adhesive systems used for bonding fiber posts under clinical conditions. Dent Mater 2002;18:495-502.

44. Perdigao J, Lopes MM, Gomes G. Interfacial adaptation of adhesive materials to root canal dentin. J Endod 2007;33:259-63.
45. Mallmann A, Jacques LB, Valandro LF, Mathias P, Muench A. Microtensile bond strength of light- and self-cured adhesive systems to intraradicular dentin using a translucent fiber post. Oper Dent 2005;30:500-6.

46. Kalkan M, Usumez A, Ozturk AN, Belli S, Eskitascioglu G. Bond strength between root dentin and three glass-fiber post systems. J Prosthet Dent 2006;96:41-6.

47. Esclassan Noirrit E, Grégoire G, Cournot M. Morphological study of fiber-reinforced post-bonding system-root dentin interface by evaluation of two bonding systems. J Dent 2008;36:204-13.

48. Perdigao J, Geraldeli S, Lee IK. Push-out bond strengths of tooth colored posts bonded with different adhesive systems. Am J Dent 2004;17:422-6.

49. Perdigao J, Lopes MM, Gomes G. Interfacial adaptation of adhesive materials to root canal dentin. J Endod 2007;33:25963.

50. Giachetti L, Grandini S, Calamai P, Fantini G, Scaminaci Russo D. Translucent fiber post cementation using light- and dual-curing adhesive techniques and a self-adhesive material: push-out test. J Dent 2009;37:638-42.

51. Kurtz JS, Perdigao J, Geraldeli S, Hodges JS, Bowles WR. Bond strengths of tooth-colored posts, effect of sealer, dentin adhesive, and root region. Am J Dent 2003;16:31-6.

52. Mallmann A, Jacques LB, Valandro LF, Mathias P, Muench A. Microtensile bond strength of light- and self-cured adhesive systems to intraradicular dentin using a translucent fiber post. Oper Dent 2005;30:500-6.

53. Mumcu E, Erdemir U, Topcu FT. Comparison of micro pushout bond strengths of two fiber posts luted using simplified adhesive approaches. Dent Mater J 2010;29:286-96.

54. Da Cunha LF, Furuse AY, Mondelli RF, Mondelli J. Compromised bond strength after root dentin deproteinization reversed with ascorbic acid. J Endod. 2010 Jan;36(1):130-4.

55. Ferracane JL. Developing a more complete understanding of stresses produced in dental composites during polymerization. Dent Mater. 2005 Jan;21(1):36-42.

56. Bonfante EA, Pegoraro LF, de Góes MF, Carvalho RM. SEM observation of the bond integrity of fiber-reinforced composite posts cemented into root canals. Dent Mater. 2008 Apr;24(4):483-91.

57. Bitter K, Paris S, Pfuertner C, Neumann K, Kielbassa AM. Morphological and bond strength evaluation of different resin cements to root dentin. Eur J Oral Sci. 2009 Jun;117(3):326-33.

58. So MVR, Saran C, Magro ML, Pelisser FVV, Munhoz M. Efficacy of ProTaper Retreatment system in root canals filled with gutta-percha and two endodontic sealers. J Endod 2008;34:1223-1225. 